\title{
ADUBAÇÃO NITROGENADA EM CAPIM-MASSAI: MORFOGÊNESE E PRODUÇÃO
}

\section{NITROGEN FERTILIZATION IN MASSAIGRASS: PRODUCTION AND MORPHOGENESIS}

\author{
Janaina Azevedo Martuscello ${ }^{1}$ \\ Luciana Pontes da Silva ${ }^{2}$ \\ Daniel de Noronha Figueiredo Vieira da Cunha ${ }^{1}$ \\ Ana Catharina dos Santos Batista ${ }^{2}$ \\ Thiago Gomes dos Santos Braz ${ }^{3}$ \\ Paulo Sérgio Ferreira ${ }^{2}$
}

${ }^{1}$ Professora do Departamento de Zootecnia da Universidade Federal de São João del-Rei, São João delRei, MG, Brasil. janaina@ufsi.edu.br

²Estudante de graduação da Universidade Federal de Alagoas, Campus Arapiraca, Arapiraca, AL, Brasil ${ }^{3}$ Professor do Departamento de Zootecnia da Universidade Federal dos Vales do Jequitinhonha e Mucuri, Diamantina, MG, Brasil

\section{Resumo:}

Objetivou-se avaliar as características morfogênicas e estruturais bem como a produção de biomassa de plantas de Panicum maximum cv. Massai sob doses de nitrogênio. O experimento foi instalado em delineamento de blocos casualizados com quatro tratamentos $(0,80,160$ e $240 \mathrm{~kg}$ de $\mathrm{N} / \mathrm{ha}$ ) e quatro repetições, em parcelas de $4 \mathrm{~m}^{2}$. A adubação nitrogenada foi aplicada parceladamente, de acordo como os tratamentos. Plantas de capim-massai responderam linear e positivamente à adubação nitrogenada com aumento significativo nas taxas de alongamento, aparecimento e senescência de folhas e alongamento de colmo bem como no número de folhas vivas por perfilhos e no comprimento final da lâmina. Por outro lado, a adubação nitrogenada diminui o filocrono e a duração de vida das folhas em capim-massai, o que indica efeito direto do nitrogênio no fluxo de tecidos. Observou-se efeito linear e positivo da adubação nitrogenada para massa seca total, de folhas e de colmos, não tendo sido observado efeito para massa seca de material morto. A adubação nitrogenda influencia o perfilhamento, a morfogênese e a produção de biomassa em plantas de capim-massai.

Palavras-chave: Fertilização; Nitrogênio; Panicum maximum.

\begin{abstract}
:
The objective of this study was to evaluate the morphogenetic and structural characteristics, as well as the biomass of Panicum maximum cv. Massai plants under nitrogen levels. The experiment was conducted in a randomized block design with four treatments $(0,80,160$ and $240 \mathrm{~kg} \mathrm{~N} / \mathrm{ha})$ and four replications in plots of $4 \mathrm{~m}^{2}$. The nitrogen was applied according to the treatments. Massaigrass
\end{abstract}


plants responded linear and positively to $\mathrm{N}$ fertilization with a significant increase in the rates of elongation, appearance and senescence of leaves, stem elongation, and number of live leaves per tiller and the final length of the blade. On the other hand, the nitrogen decreased the phyllochron and leaf life span of the massaigrass, indicating a direct effect of nitrogen flow in the tissues. There was positive and linear effect of $\mathrm{N}$ fertilization on total dry matter of leaf and stem, but there was no effect on dry matter of dead material. Nitrogen fertilization influences tillering, morphogenesis and biomass production in massaigrass plants.

Keywords: fertilization; nitrogen; Panicum maximum.

Recebido em: 29 maio 2012.

Aceito em: 26 nov. 2014.

\section{Introdução}

$\mathrm{Na}$ maioria dos estados do nordeste brasileiro, a produtividade das pastagens é baixa, o que pode estar relacionado à distribuição irregular de chuvas, além da baixa disponibilidade de tecnologias específicas para a produção animal nessa região. Devido à distribuição irregular das chuvas, são poucas as opções de forrageiras para a região, havendo, assim, necessidade de investigações acerca da adaptabilidade de cultivares disponíveis no mercado. A espécie forrageira Panicum maximum Jacq. é conhecida por sua alta produtividade, sobretudo quando submetida a condições edafoclimáticas e de manejo adequadas ${ }^{(1)}$. Dentre as cultivares de P. maximum, o cultivar massai destaca-se pela alta capacidade de emissão de folhas e perfilhos, sendo promissor para os sistemas de produção de ruminantes ${ }^{(2)}$. Apesar disso, poucos são os estudos com essa forrageira na região nordeste.

A compreensão do processo de desenvolvimento das forrageiras, a partir da morfogênese, torna-se importante para a definição de estratégias racionais de manejo de pastagens. Diversos estudos têm sido conduzidos para avaliar o efeito da adubação nitrogenada sobre as características morfogênicas e estruturais de gramíneas forrageiras ${ }^{(2-4)}$; entretanto, poucos são aqueles conduzidos na região Nordeste, com destaque para a ausência de estudos no Agreste de Alagoas. Daí a importância de investigações que possam nortear recomendações de uso de forrageira e de adubação para os produtores dessa região. A realização de estudos sobre a adaptabilidade do capim-massai adubado com nitrogênio pode indicar o potencial de uso dessa forrageira na região Nordeste.

Diante do exposto, objetivou-se avaliar a produção, morfogênese e dinâmica de perfilhamento do capim-massai adubado com nitrogênio.

\section{Material e Métodos}

O trabalho foi conduzido em área experimental da Universidade Federal de Alagoas/Campus Arapiraca no período de maio a setembro de 2009. O município de Arapiraca situa-se na região do agreste sub-úmido, onde o clima é do tipo As', segundo a classificação climática de Köppen, com estação seca no verão e chuvas de outono/inverno. 
O solo da área experimental, classificado como Latossolo Vermelho-Amarelo ${ }^{(5)}$, foi coletado e avaliado quanto às características químicas apresentando os seguintes valores: $\mathrm{pH}\left(\mathrm{H}_{2} \mathrm{O}\right): 5,4 ; \mathrm{Ca}^{+2}$ : $4,7 \mathrm{cmol}_{\mathrm{c}} / \mathrm{dm}^{3} ; \mathrm{Mg}^{+2}: 2,2 \mathrm{cmol}_{\mathrm{c}} / \mathrm{dm}^{3} ; \mathrm{Al}^{+3}: 0 \mathrm{cmol}_{\mathrm{c}} / \mathrm{dm}^{3} ; \mathrm{H}+\mathrm{Al}: 4 \mathrm{cmol}_{\mathrm{c}} / \mathrm{dm}^{3} ; \mathrm{SB}: 7,23 \mathrm{cmol}_{\mathrm{c}} / \mathrm{dm}^{3} ;$ CTC: $11,23 \mathrm{cmol}_{\mathrm{c}} / \mathrm{dm}^{3} ; \mathrm{V}(\%): 64,4 ; \mathrm{P}-68 \mathrm{mg} / \mathrm{dm}^{3}$ e K $\mathrm{K}^{+}-142 \mathrm{mg} / \mathrm{dm}^{3}$.

Os tratamentos consistiram em quatro doses de nitrogênio $(0,80,160$ e $240 \mathrm{~kg} / \mathrm{ha})$. O delineamento experimental foi em blocos casualizados com quatro repetições. O capim-massai foi semeado em sulcos, em parcelas de $4 \mathrm{~m}^{2}$, em densidade equivalente a 25 plantas $/ \mathrm{m}^{2}$. Durante o estabelecimento, foram aplicados $20 \mathrm{~kg} / \mathrm{ha}$ de $\mathrm{P}_{2} \mathrm{O}_{5}$, na forma de superfosfato simples, nas linhas de plantio ${ }^{(6)}$.

A adubação nitrogenada foi aplicada de acordo com os tratamentos utilizando-se a ureia como fonte de nitrogênio e parcelada em três aplicações. A primeira dose foi aplicada imediatamente após o corte de uniformização (cerca de 30 dias após a semeadura) e a segunda e terceira doses 45 e 60 dias após a semeadura, respectivamente. Em cada parcela aplicou-se o equivalente a $60 \mathrm{~kg} / \mathrm{ha} \mathrm{de}$ $\mathrm{K}_{2} \mathrm{O}$ (cloreto de potássio), concomitantemente com a aplicação das doses de nitrogênio ${ }^{(6)}$. Um segundo ciclo de adubação, idêntico ao primeiro, foi realizado após o terceiro corte.

As características morfogênicas foram avaliadas duas vezes por semana, com uso de régua milimetrada, em dois perfilhos por parcela, marcados aleatoriamente após o corte de uniformização. O comprimento das folhas expandidas foi determinado por meio de medição desde a ponta da folha até sua lígula. No caso de folhas em expansão, o mesmo procedimento foi adotado, porém considerou-se a lígula da última folha expandida como referencial de mensuração. A partir dessas mensurações, foram calculadas as seguintes variáveis-respostas: taxa de aparecimento foliar (TApF, em $\mathrm{cm} /$ dia), taxa de alongamento foliar (TAlF, em $\mathrm{cm} /$ dia), filocrono (número de dias necessários para o aparecimento de duas folhas consecutivas), número de folhas vivas por perfilho (NFV), duração de vida das folhas (DVF, em dias) e taxa de senescência foliar (TSeF, em cm/dia).

Para avaliação da produção de massa seca foram realizados cinco cortes. Em cada corte, uma moldura de $1 \mathrm{~m}^{2}$ foi alocada aleatoriamente na parcela quando as plantas atingiam $50 \mathrm{~cm}$ de altura. Toda forragem situada dentro da moldura foi cortada a $10 \mathrm{~cm}$ do nível do solo e pesada para obtenção da produção de matéria verde total (MVT). Logo após, as amostras foram separadas em seus componentes morfológicos: lâmina, colmo + bainha e material morto. Depois de pesados, estes componentes foram desidratados em estufa de ventilação forçada a $55^{\circ} \mathrm{C}$ até o peso constante para estimativa da produção de massa seca total (MST), massa seca foliar (MSF), massa seca de colmo (MSC) e massa seca de material morto (MSMM). Todos os componentes botânicos foram moídos e aproximadamente $3 \mathrm{~g}$ de cada amostra moída foram secas em estufa a $105^{\circ} \mathrm{C}$, a fim de corrigir a estimativa do teor de MS da forragem.

A dinâmica de perfilhamento e as respectivas taxas de aparecimento e mortalidade de perfilho foram avaliadas em duas touceiras (unidade de amostragem) por parcela. As touceiras foram escolhidas aleatoriamente e eram distintas daquelas utilizadas para avaliação das características morfogênicas. No início do período experimental, todos os perfilhos existentes em cada uma das duas touceiras foram contados e marcados com arames revestidos de plástico de determinada cor. A cada nova amostragem, novos perfilhos eram identificados e marcados com cores diferentes. $\mathrm{O}$ intervalo entre marcações foi de 21 dias. Assim, determinou-se a dinâmica da população de perfilhos de todas as gerações (cores diferentes), o que permitiu o acompanhamento da evolução do número de perfilhos por touceira. Os dados de cada repetição foram utilizados para se estimar o número médio de perfilhos para cada tratamento. De posse desses dados, foram calculadas as taxas 
de aparecimento (TApP), mortalidade (TMoP) e sobrevivência de perfilhos (TSoP), de acordo com as seguintes fórmulas:

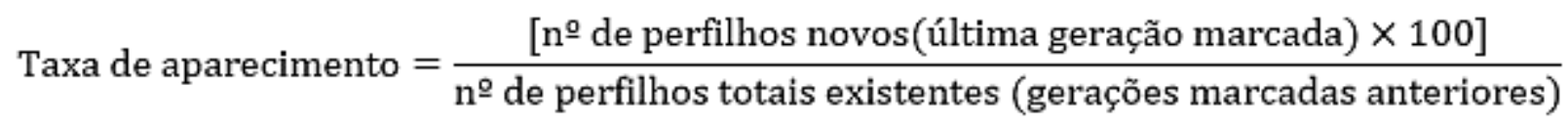

Taxa de mortalidade $=\frac{(\text { perfilhos marcados anteriores }- \text { perfilhos sobreviventes } \times 100)}{n^{2} \text { total de perfilhos da marcação anterior }}$

Taxa de sobrevivência $=\frac{\left(\mathrm{n}^{\circ} \text { de perfilhos da marcação anterior vivos na marcação atual } \times 100\right)}{\mathrm{n}^{\circ} \text { de perfilhos vivos na marcação anterior }}$

Os dados de morfogênese, produção e as taxas de aparecimento, mortalidade e sobrevivência foram submetidos à análise de regressão em função das doses de nitrogênio, selecionando-se as equações pelo coeficiente de determinação $\left(\mathrm{r}^{2}\right)$ e pelo nível de significância dos coeficientes de acordo com o teste t. Adotou-se 5\% como nível crítico de probabilidade para o erro do tipo I. As equações de regressão foram ajustadas com base nas médias de tratamentos, sendo o $\mathrm{r}^{2}$ obtido por meio do quociente entre a soma de quadrados da regressão e a soma de quadrados total. Os dados da dinâmica de perfilhamento foram avaliados por estatística descritiva utilizando-se o erro padrão da média como medida de dispersão.

\section{Resultados e Discussão}

A taxa de alongamento foliar (TAlF) foi influenciada pela adubação nitrogenada, com os dados ajustados a modelos lineares positivos (Figura 1). Uma série de trabalhos avaliando os efeitos do nitrogênio (N) sobre a taxa de alongamento foliar também mostrou resultados semelhantes ${ }^{(2,7-9)}$.

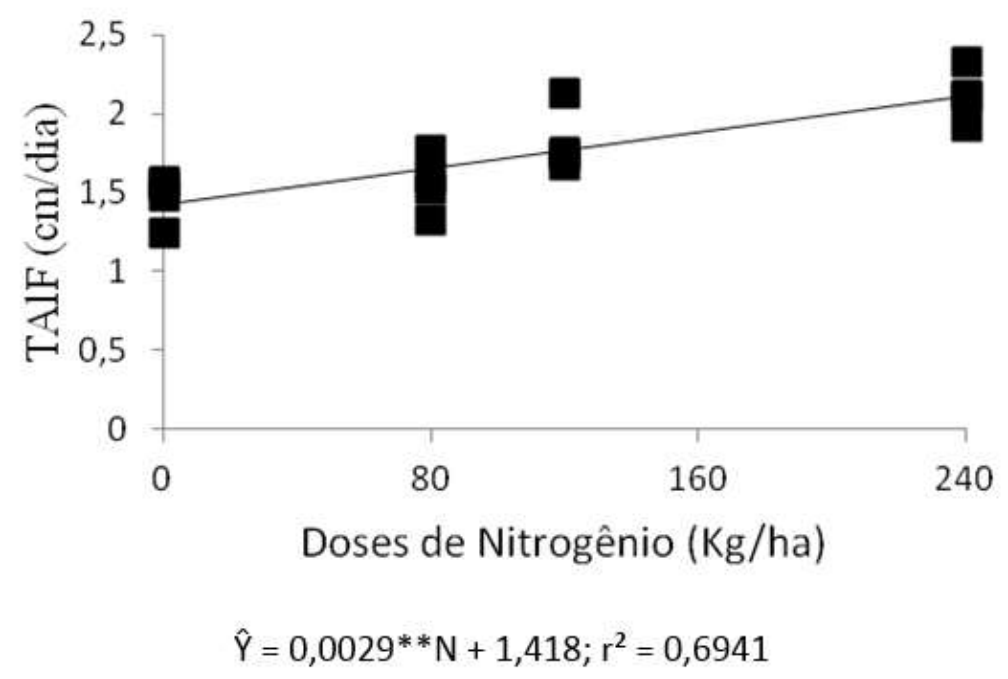

Figura 1: Taxa de Alongamento foliar (TAlF) em plantas de capim-massai submetidas a doses de nitrogênio. 
A TAlF é uma medida de grande importância na análise de fluxo de tecidos das plantas e correlaciona-se positivamente com o rendimento forrageiro (Tabela 1), já que, à medida que se aumenta a TAlF, há incremento na proporção de folhas e, consequentemente, maior área foliar fotossinteticamente ativa, promovendo, assim, maior acúmulo de massa seca ${ }^{(2)}$. De fato, observouse correlação positiva e significativa entre a TAlF e a produção de MST, MSF e MSC (Tabela 1).

Tabela 1: Correlação de Pearson e significância (entre parênteses) entre características morfogênicas e produção de massa seca em plantas de capim-massai submetidas a doses de nitrogênio

\begin{tabular}{lllll}
\hline Variável morfogênica & \multicolumn{4}{c}{ Características de produção } \\
\cline { 2 - 5 } & MST & MSF & MSC & MSMM \\
\hline TAlF & 0,82073 & 0,81724 & 0,80732 & $-0,00716$ \\
TApF & $(<0,0001)$ & $(0,0002)$ & $(0,0002)$ & $(0,9790)$ \\
& 0,68875 & 0,67437 & 0,80835 & $-0,06902$ \\
Filocrono & $(0,0032)$ & $(0,0042)$ & $(0,0002)$ & $(0,7995)$ \\
& $-0,73449$ & $-0,72147$ & $-0,82911$ & 0,04139 \\
TAlC & $(0,0012)$ & $(0,0016)$ & $(<0,0001)$ & $(0,8790)$ \\
& 0,89541 & 0,68951 & 0,89953 & $-0,00642$ \\
DVF & $(<0,0001)$ & $(0,0002)$ & $(<0,0001)$ & $(0,6872)$ \\
& $-0,78378$ & $-0,79011$ & $-0,69110$ & 0,09531 \\
NFV & $(0,0003)$ & $(0,0003)$ & $(0,003)$ & $(0,7255)$ \\
& 0,67651 & 0,65923 & 0,80841 & $-0,00593$ \\
CFL & $(0,0040)$ & $(0,0055)$ & $(0,0002)$ & $(0,9826)$ \\
& 0,87877 & 0,81724 & 0,90183 & 0,13820 \\
TSeF & $(<0,0001)$ & $(<0,0001)$ & $(<0,0001)$ & $(0,6098)$ \\
& 0,44828 & 0,4577 & 0,39142 & $-0,4592$ \\
\hline & $(0,0816)$ & $(0,0782)$ & $(0,1338)$ & $(0,8659)$ \\
\hline
\end{tabular}

TAlF: Taxa de alongamento foliar; TApF: taxa de aparecimento foliar, TAlC: taxa de alongamento de colmo, NFV: número de folhas vivas, DVF: duração de vida das folhas, CFL: comprimento final das lâminas, MSF: massa seca da lâmina, MSC: massa seca do colmo, MSMM: massa seca do material morto, MST: massa seca total (MST).

A TApF foi influenciada $(\mathrm{P}=0,0002)$ pela adubação nitrogenada, com ajuste linear e positivo (Figura 2).

Estudos com capim-massai são ainda incipientes na região Nordeste, não havendo, portanto, base comparativa para a taxa de aparecimento foliar dessa forrageira; entretanto, observam-se valores menores que aqueles reportados por outros autores em trabalhos conduzidos em outras regiões do Brasil $^{(2)}$. Isso pode ser explicado pela menor precipitação nessa região, o que interfere diretamente nas características morfogênicas. De qualquer forma, a influência do nitrogênio na TApF pode ser analisada como resultado da combinação de vários fatores, como altura de bainha, alongamento foliar e temperatura ${ }^{(10)}$. Garcez Neto et al. (2002), em trabalho com quatro doses de nitrogênio (ausência de aplicação, 100, 200 e $400 \mathrm{~kg} / \mathrm{ha})$ e três alturas de corte $(5,10$ ou $20 \mathrm{~cm}$ ) em capim- 
mombaça, observaram aumentos de até $104 \%$ na TApF. Por outro lado, Patês et al. ${ }^{(11)}$, avaliando o efeito da aplicação de nitrogênio e fósforo sobre a morfogênese do capim-tanzânia, observaram aumento médio de 59\% na TApF, com a aplicação de 100 kg/ha.ano.

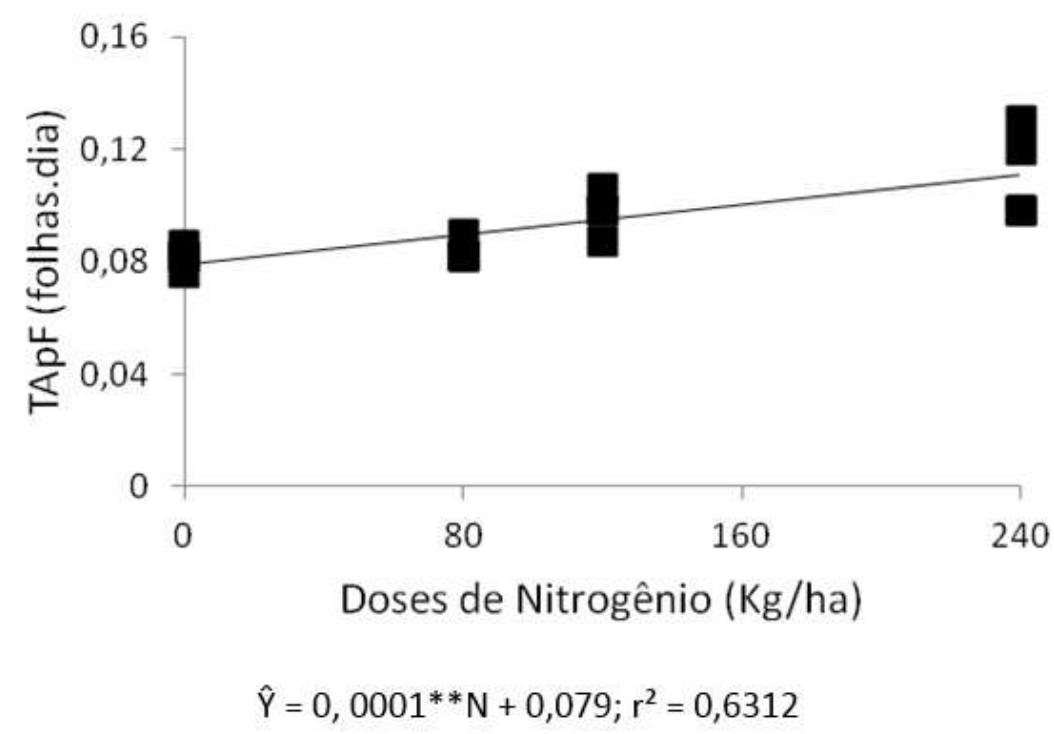

Figura 2: Taxa de aparecimento foliar (TAlF) em plantas de capim-massai submetidas a doses de nitrogênio.

Observa-se na Tabela 1 correlação positiva e significativa entre a TApF e a produção de massa seca, excetuando-se a produção de massa seca do material morto (MSMM). Isso é indicativo de que o aumento no número de folhas pode representar ganhos expressivos na produção de biomassa. De fato, observa-se alta correlação entre o NFV e a produção de MST, MSF e MSC (Tabela 1).

$\mathrm{O}$ filocrono, que é o inverso da $\mathrm{TApF}$, foi influenciado $(\mathrm{P}=0,003)$ pela adubação nitrogenada com os dados ajustados ao modelo linear negativo ( $\left.\hat{\mathrm{Y}}=-0,014 * * \mathrm{~N}+12,44 ; \mathrm{r}^{2}=0,6635 ;\right)$. Os valores do filocrono variaram de 12,448 dias para plantas sem adubação nitrogenada a 9,08 dias para plantas adubadas com $240 \mathrm{mg} / \mathrm{dm}^{3}$ de $\mathrm{N}$. O filocrono é definido como o intervalo de aparecimento entre duas folhas consecutivas e, de acordo com os resultados, pode-se inferir que o nitrogênio diminui o tempo necessário para a expansão das folhas. Nesse sentido, Martuscello et al. ${ }^{(2)}$ verificaram, em plantas de capim-massai, influência tanto da adubação nitrogenada quanto do regime de desfolhação sobre o filocrono, que diminuiu nas doses mais altas e com as menores frequências de desfolhação. De acordo com esses autores, a redução do filocrono com a adubação nitrogenada resulta do efeito do $\mathrm{N}$ sobre o crescimento das plantas, conferindo maior capacidade de rebrotação, visto que, após a desfolhação, a rápida recuperação de seu aparato fotossintético pode determinar sua sobrevivência na comunidade vegetal. Esse resultado também foi observado por Garcez Neto et al. ${ }^{(12)}$, que encontraram redução no intervalo para a emissão de duas folhas consecutivas em função do aumento das doses de nitrogênio. Ainda segundo esses autores, a taxa de alongamento, ao responder ao suprimento de nitrogênio, seria o principal agente modificador da taxa de aparecimento foliar, pois o aparecimento de folhas sucessivas em níveis de inserção muito próximos, mas sob elevadas taxas de alongamento, estabeleceriam maior taxa de aparecimento foliar. 
O filocrono correlaciona-se negativamente com a produção de MST, MSF e MSC (Tabela 1), o que pode ser explicado pelo fato de que quanto maior o filocrono, menor a produção de biomassa, com destaque para produção de MSF, uma vez que maior seria o tempo necessário para a expansão de uma nova folha.

A TAlC respondeu linear e positivamente à adubação nitrogenada (Figura 3), assim, observaram-se maiores valores para os tratamentos com maior adubação, uma vez que nessa situação o autosombreamento exercido pelas plantas de capim-massai promove maior necessidade de alongamento não só das folhas como também dos colmos. Portanto, em condições de baixa luminosidade as plantas podem priorizar a produção de colmos, no intuito de captar uma quantidade maior de energia luminosa.

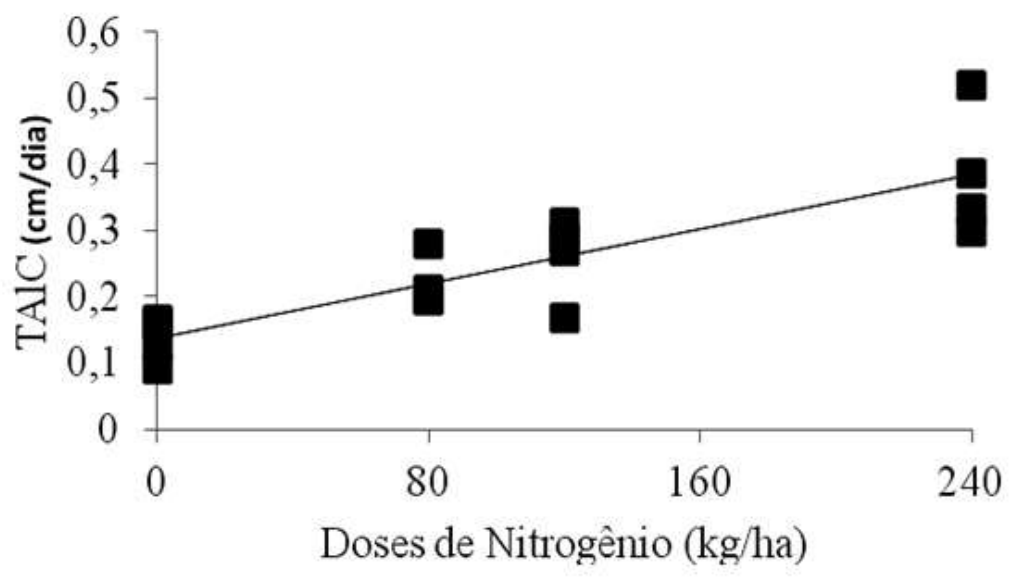

$\hat{\mathrm{Y}}=0,002 * * \mathrm{~N}+0,136 ; \mathrm{r}^{2}=0,7243$

Figura 3: Taxa de alongamento de colmo (TAlC) em plantas de capim-massai submetidas a doses de nitrogênio.

Observa-se na Tabela 1 correlação altamente significativa entre a TAlC e a produção de MST e MSC. Isso corrobora a afirmação de que o nitrogênio aumenta a produção de massa, por incrementar sobremaneira a produção de colmo, o que, entretanto, pode não significar decréscimo acentuado na qualidade da dieta, uma vez que há também aumento no alongamento de folhas, conforme observado na Figura 1.

$\mathrm{O}$ número de folhas vivas $(\mathrm{NFV})$ por perfilho aumentou $(\mathrm{P}=0,005)$ à medida que se incrementou a adubação nitrogenada $\left(\hat{\mathrm{Y}}=0,0056^{*} \mathrm{~N}+2,6375 ; \mathrm{r}^{2}=0,5916\right)$. Observou-se que o NFV variou de 2,63 a 3,98 para ausência de adubação e aplicação de $240 \mathrm{~kg} / \mathrm{ha}$ de N, respectivamente. O NFV é uma característica determinada geneticamente, mas responde às variações de clima e solo, podendo diminuir em condições de estresse. Embora a adubação nitrogenada tenha aumentado o NFV, plantas de capim-massai recebendo doses de nitrogênio de $240 \mathrm{~kg} / \mathrm{ha}$ apresentaram baixo NFV quando se compara com dados de outra região do país. Martuscello et al. ${ }^{(2)}$ observaram NFV variando de 4 a 5,77 para as doses de 0 a $120 \mathrm{mg} / \mathrm{dm}^{3}$ de $\mathrm{N}$, respectivamente.

A DVF respondeu linear e negativamente $(\mathrm{P}<0,001)$ à adubação nitrogenada (Figura 4). Mazzanti et al. ${ }^{(13)}$ ressaltam que, em geral, ocorre diminuição nessa variável em alta disponibilidade de $\mathrm{N}$, em função de concorrência por luz, determinada pelo aumento da taxa de alongamento foliar e pelo maior tamanho final das folhas. Os resultados de DVF podem ser mais bem entendidos quando são analisados em conjunto com a taxa de senescência (TSeF). Nesse sentido, observou-se uma 
correlação negativa de $0,26(\mathrm{P}<0,05)$ entre essas variáveis. À medida que se incrementou a adubação nitrogenada, observou-se aumento significativo da TSeF (Figura 5). Isso pode ser devido ao fato de que plantas, na ausência de $\mathrm{N}$, apresentam baixa TSeF foliar, como uma estratégia para permanecerem vivas devido, provavelmente, a seu decréscimo no metabolismo.

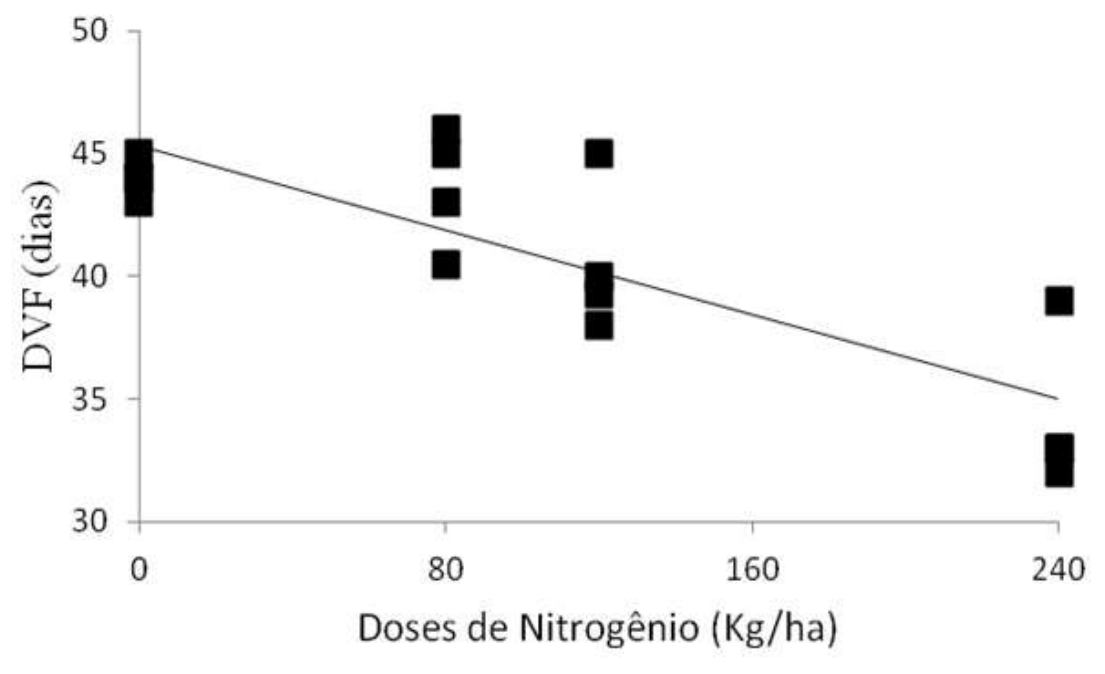

$$
\hat{\mathrm{Y}}=0,043^{* *} \mathrm{~N}+45,34 ; \mathrm{r}^{2}=0,6880
$$

Figura 4: Duração de vida das folhas (DVF) em plantas de capim-massai submetidas a doses de nitrogênio.

Outra característica que pode auxiliar o entendimento da relação DVF e NFV é o CFL, que respondeu linear e positivamente $(\mathrm{P}=<0,0001)$ à adubação nitrogenada $\left(\hat{\mathrm{Y}}=0,0987 * * \mathrm{~N}+24,95 ; \mathrm{r}^{2}\right.$ $=0,7707)$. Ao se considerar que o número de folhas revela o potencial fotossintético da planta, os dados evidenciam que o $\mathrm{N}$ pode aumentar o NFV e o CFL incrementando sua capacidade de assimilação de carbono ${ }^{(2,7-9)}$. De fato, observou-se correlação positiva e altamente significativa entre o CFL e a produção de MST, MSF e MSC (Tabela 1).

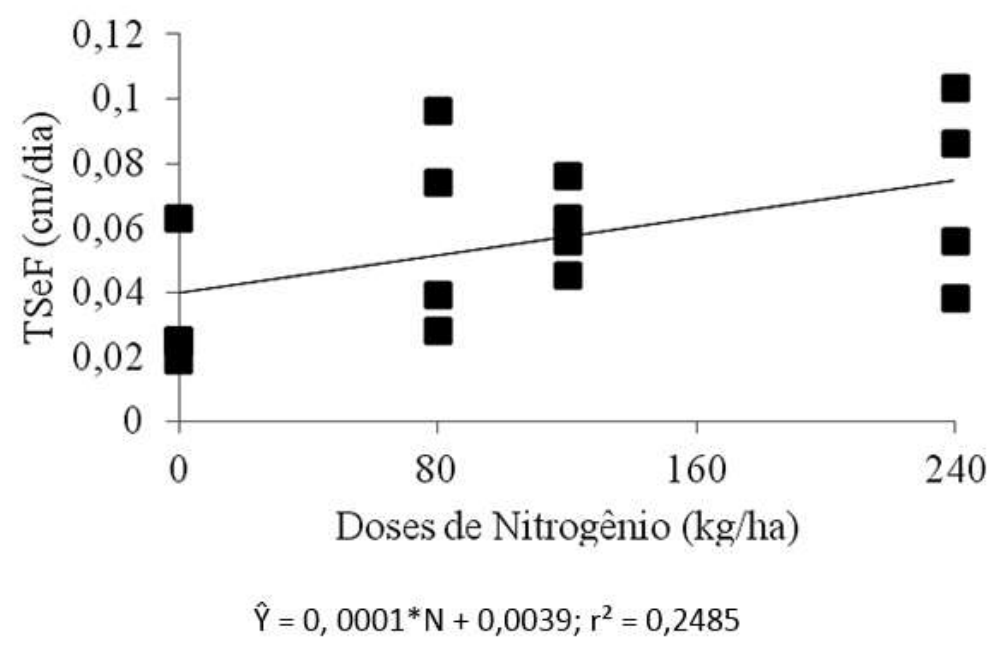

Figura 5: Taxa de Senescência foliar (TSeF) em plantas de capim-massai submetidas a doses de nitrogênio. 
A taxa de aparecimento de perfilhos (TApP) foi influenciada $(\mathrm{P}=0,003)$ linear e positivamente pela adubação nitrogenada (Tabela 2). De fato, o nitrogênio age como estimulador do perfilhamento ${ }^{(7,9)}$. $\mathrm{O}$ efeito positivo do $\mathrm{N}$ sobre o perfilhamento pode ser explicado pela maior capacidade de formação das gemas axilares e à iniciação dos perfilhos correspondentes para as plantas que receberam adubação. Assim, a aplicação de nitrogênio em gramíneas forrageiras pode aumentar a brotação de gemas axilares, resultando em maior número de novos perfilhos no pasto e, consequentemente, maior taxa de aparecimento de perfilhos. Embora, a adubação nitrogenada tenha influenciado positivamente a TApP, não houve efeito das doses de nitrogênio para as taxas de mortalidade $(\mathrm{P}=0,078)$ e sobrevivência $(\mathrm{P}=0,085)$ de perfilhos (Tabela 2), com médias de 15,02 e 89,11\%, respectivamente. De forma geral, o nitrogênio induz não somente o aparecimento de perfilhos, mas também a mortalidade, uma vez que aumenta o fluxo de tecidos.

Tabela 2: Equações de regressão para características avaliadas de perfilhamento em Panicum maximum x Panicum infestum $\mathrm{cv}$. Massai em função das doses de nitrogênio $(0,80,160$ e $240 \mathrm{~kg} / \mathrm{ha})$

\begin{tabular}{ll}
\hline Características Avaliadas & Equações \\
\hline TApP & $\hat{\mathrm{Y}}=18,66+0,2314 \mathrm{~N}^{*} ; \mathrm{r}^{2}=70,54$ \\
TMoP & $\mathrm{Y}=15,02$ \\
TSoP & $\mathrm{Y}=89,11$ \\
\hline
\end{tabular}

TApP: taxa de aparecimento de perfilho; TMoP : taxa de mortalidade de perfilhos; TSoP: taxa de sobrevivência de perfilhos;

* significativo a $5 \%$ de probabilidade pelo teste $\mathrm{t}$.

Na Tabela 3 observa-se o número de perfilhos por geração. Analisando-se o número de perfilhos nas diferentes doses de nitrogênio, observou-se maior número de perfilhos na dose de $160 \mathrm{~kg} / \mathrm{ha}$ de $\mathrm{N}$, até a quarta geração, a partir daí observou-se maior número de perfilhos para ausência de adubação. Isso pode ser explicado pelo fato de que plantas de capim-massai adubadas com nitrogênio tendem a aumentar a deposição de massa seca, o que promove maior sombreamento e, consequentemente, menor número de perfilhos, uma vez que a luz também age como indutora de perfilhamento. Essa informação, juntamente com o déficit hídrico, pode explicar a queda no número de perfilhos ao longo das gerações. As gerações 1 até 4 foram avaliadas no período de águas e as demais no período de transição água-seca e seca. É sabido que a água é um dos fatores abióticos mais importantes na produção de massa seca de forragem e, sendo o perfilhamento a unidade básica de formação de uma planta forrageira, a disponibilidade hídrica tem efeito direto no perfilhamento. Nessas condições é possível observar que o Agreste alagoano possui condições adversas de déficit de água em épocas secas, apresentando concentração de distribuição de água no inverno e poucas chuvas no período de janeiro-fevereiro, sendo estas informações, bem como o estabelecimento de estratégias de manejo correto, inclusive de adubação, de grande importância na avaliação e seleção de plantas forrageiras adaptadas à região. $\mathrm{O}$ maior número de perfilhos na primeira geração se dá pela ausência de competição, que é decorrente do sincronismo entre o desenvolvimento das folhas e o perfilhamento. 
Tabela 3: Número médio de perfilhos basilares/geração em capim-massai e seus respectivos erros padrões da média em função das doses de nitrogênio $(0,80,160$ e 240 $\mathrm{kg} / \mathrm{ha})$

\begin{tabular}{ccccc}
\hline \multirow{2}{*}{$\begin{array}{c}\text { Geração de } \\
\text { Perfilhos }\end{array}$} & \multicolumn{4}{c}{ Doses de Nitrogênio (kg/ha) } \\
\cline { 2 - 5 } & $\mathbf{0}$ & $\mathbf{8 0}$ & $\mathbf{1 6 0}$ & $\mathbf{2 4 0}$ \\
\hline & & & & \\
1 & $8,81 \pm 0,99$ & $4,87 \pm 0,62$ & $15,9 \pm 1,51$ & $6,17 \pm 0,98$ \\
2 & $5,73 \pm 0,66$ & $9,85 \pm 0,79$ & $10,32 \pm 1,24$ & $8,42 \pm 1,53$ \\
4 & $1,77 \pm 0,49$ & $1,75 \pm 0,16$ & $3,02 \pm 0,39$ & $2,62 \pm 0,86$ \\
5 & $1,92 \pm 0,18$ & $1,07 \pm 0,08$ & $1,9 \pm 0,19$ & $1,57 \pm 0,27$ \\
6 & $3,93 \pm 0,16$ & $0,65 \pm 0,03$ & $0,9 \pm 0,11$ & $1,68 \pm 0,10$ \\
7 & $1,7 \pm 0,18$ & $0,5 \pm 0$ & $0,87 \pm 0,12$ & $0,16 \pm 0,04$ \\
8 & 0 & 0 & $0,12 \pm 0$ & $0,18 \pm 0,19$ \\
& $0,62 \pm 0$ & $0,62 \pm 0$ & $3,5 \pm 0$ & $1,5 \pm 0$ \\
\hline
\end{tabular}

Em relação à produção de massa seca, observou-se efeito linear e positivo $(\mathrm{P}<0,0001)$ da adubação nitrogenada para MST (Figura 6), MSF (Figura 7) e MSC (Figura 7), não tendo sido observado efeito $(\mathrm{P}=0,6753)$ para MSMM $(\hat{\mathrm{Y}}=12,01)$. $\mathrm{O}$ aumento da produção do capim-massai com $\mathrm{o}$ incremento das doses de $\mathrm{N}$ é explicado pelo fato de o $\mathrm{N}$ agir como fator controlador dos diferentes processos de crescimento e desenvolvimento das plantas, proporcionando aumento de biomassa pela fixação de carbono ${ }^{(7,8)}$. Vários estudos foram conduzidos nesse sentido, em que se observaram aumento significativo na produção de massa seca a medida que se incrementou a adubação nitrogenada $^{(2-4)}$.

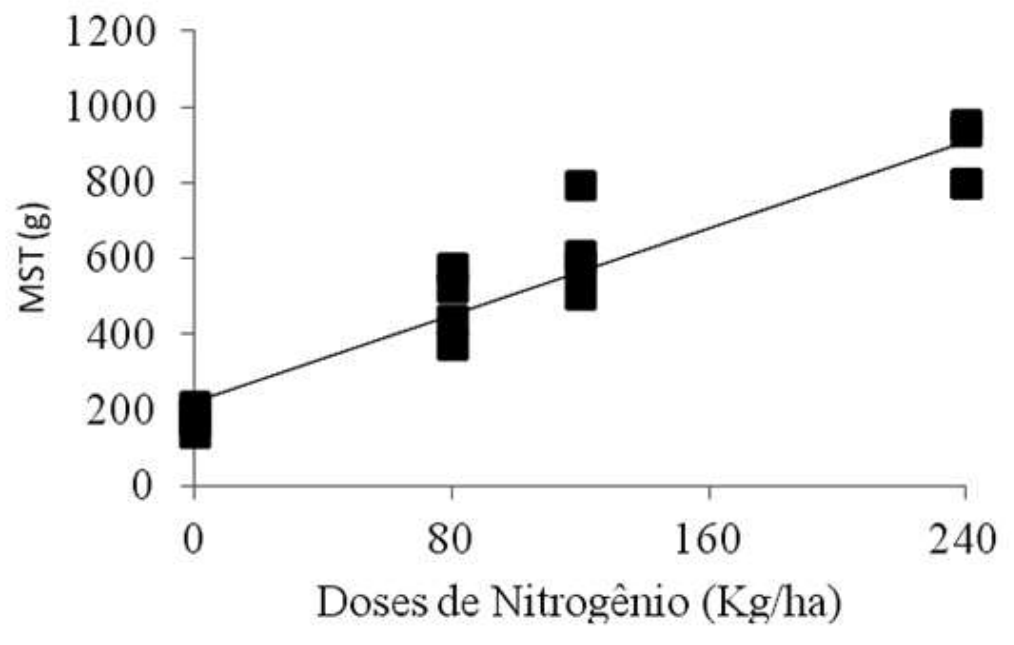

$$
\hat{\mathrm{Y}}=2,7757 * \mathrm{~N}+202,71 ; \mathrm{r}^{2}=0,8993
$$

Figura 6: Produção de massa seca total (MST) em plantas de capim-massai submetidas a doses de nitrogênio.

A produção de MS laminar é uma característica importante para o crescimento das forrageiras, uma vez que a lâmina é o componente mais fotossinteticamente ativo na folha. À semelhança da lâmina 
foliar, a produção de MS de colmo do capim-massai também aumentou com as doses de N. De forma geral, a adubação promoveu aumento no rendimento forrageiro devido à maior eficiência fotossintética das folhas, intenso perfilhamento e alongamento do colmo que, por sua vez, determinou alterações indesejáveis na qualidade da forragem pela diminuição da relação lâmina:colmo. Pode-se admitir que o alongamento de colmo de capim-massai neste experimento e seu consequente aumento de peso não tenha sido suficiente para interferir na qualidade da forragem, uma vez que a produção de lâmina foliar também apresentou comportamento linear positivo à medida que se incrementou a adubação nitrogenada.

Também Martuscello et al. ${ }^{(2)}$ observaram efeito positivo da adubação nitrogenada na produção de MST, MSF e MSC em plantas de capim-massai sob doses de nitrogênio. Segundo os autores, a maior produção de MS de lâminas foliares com as doses de nitrogênio é coerente com a maior AF dessas plantas, uma vez que constataram alta correlação $(\mathrm{P}<0,05)(\mathrm{r}=0,88)$ entre essas duas variáveis.

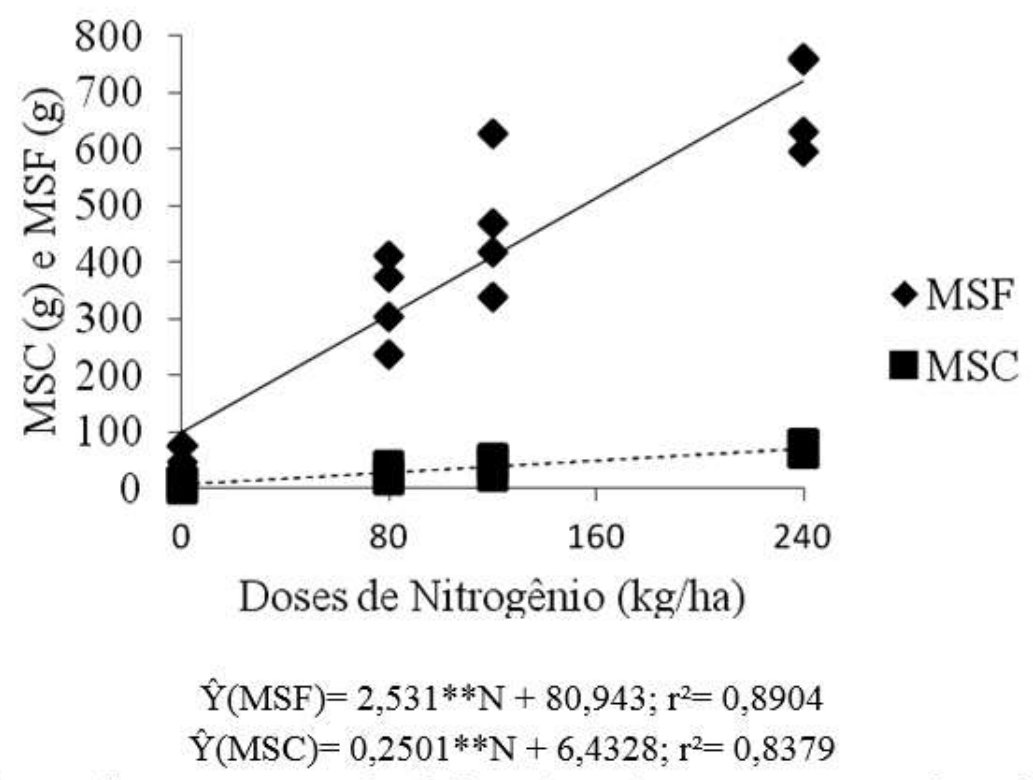

Figura 7: Produção de massa seca de folhas (MSF) e massa seca de colmos (MSC) em plantas de capim-massai submetidas a doses de nitrogênio.

\section{Conclusão}

A morfogênese e a produção de massa seca do capim-massai são influenciadas positivamente pela adubação nitrogenada.

A adubação nitrogenda influencia o perfilhamento em plantas de capim-massai. O número de perfilhos basilares no capim-massai é maior para a dose de $160 \mathrm{~kg} / \mathrm{ha}$ de nitrogênio em diferentes periodos do ano. 


\section{Referências}

1. Jank L, Valle CB, Resende, RMS. Breeding tropical forages. Crop Breeding and Applied Biotechnology. 2011;1: p.27-34.

2. Martuscello JA, Fonseca DM, Nascimento Jr D, Santos PM, Cunha DNFV. Características morfogênicas e estruturais de capim-massai submetido a adubação nitrogenada e desfolhação. Revista Brasileira de Zootecnia. 2006;35(3):665-671. Disponível em http://dx.doi.org/10.1590/S1516-35982006000300006. Acesso em 23 janeiro de 2015.

3. Alexandrino E, Nascimento Jr. D, Mosquim PR, Regazzi AJ, Rocha FC. Características morfogênicas e estruturais na rebrotação da Brachiaria brizantha cv. Marandu submetida a três doses de nitrogênio. Revista Brasileira de Zootecnia. 2004; 33(6): 1372-1379. Disponível em http://dx.doi.org/10.1590/S151635982004000600003. Acesso e 23 janeiro de 2015.

4. Martuscello JA, Fonseca DM, Nascimento Jr D, Santos PM, Ribeiro Jr JI, Cunha DNFV, Moreira LM. Características morfogênicas e estruturais do capim-xaraés submetido à adubação nitrogenada e desfolha. Revista Brasileira de Zootecnia. 2005;34(5):1475-1482. Disponível em http://dx.doi.org/10.1590/S151635982005000500007. Acesso em 23 janeiro de 2015.

5. Empresa Brasileira de Pesquisa Agropecuária-EMBRAPA. Centro Nacional de Pesquisa de Solos. Sistema Brasileiro de Classificação de Solos. Rio de Janeiro, 1999. 412p. Portuguese. Disponível em http://www.agrolink.com.br/downloads/sistema-brasileiro-de-classificacao-dos-solos2006.pdf

6. Cantarutti RB, Martins CE, Carvalho MM de, Fonseca DM, Arruda ML, Vilela, H. Oliveira, F.T.T. de. Pastagens. In: Ribeiro AC, Guimarães PTG, Alvarez VH (Ed.). Recomendações para o uso de corretivos e fertilizantes em Minas Gerais: 5a aproximação. Viçosa - MG: UFV; 1999. p. 332-341. Portuguese.

7. Fagundes JL, Fonseca DM, Mistura C, Morais RV, Vitor CMT, Gomide JA, Nascimento Jr D, Casagrande, DR, Costa LT. Características morfogênicas e estruturais do capim-braquiária em pastagem adubada com nitrogênio avaliadas nas quatro estações do ano. Revista Brasileira de Zootecnia. 2006; 35 (1):21-29. Disponível em http://dx.doi.org/10.1590/S1516-35982006000100003. Acesso em 23 janeiro de 2015 .

8. Braz TGS, Fonseca DM, Freitas FP, Martuscello JA, Santos ME, Santos MV. Morphogenesis of Tanzania guinea grass under nitrogen doses and plant densities. Revista Brasileira de Zootecnia. 2011; 40 (7):14201427. Disponível em http://dx.doi.org/10.1590/S1516-35982011000700004. Acesso em 23 janeiro de 2015.

9. Pereira VV, Fonseca D, Martuscello J, Braz TGS, Santos MV, Cecon PR. Características morfogênicas e estruturais de capim-mombaça em três densidades de cultivo adubado com nitrogênio. Revista Brasileira de Zootecnia. 2011;12(4):2681-2689. Disponível em http://www.scielo.br/pdf/rbz/v40n12/10.pdf. Acesso em 23 janeiro de 2015.

10. Duru M, Ducrocq H. Growth and senescence of the successive grass leaves on a tiller. Ontogenic development and effect of temperature. Annals of Botany. 2000; 85:635-643. Disponível em: http://dx.doi.org/10.1006/anbo.2000.1116. Aceso em 23 janeiro de 2015.

11. Patês NMS, Pires AJV, Silva CCF. Características morfogênicas e estruturais do capim-tanzânia submetido a doses de fósforo e nitrogênio. Revista Brasileira de Zootecnia. 2007;36(6):1736-1741. Disponível em http://www.scielo.br/pdf/rbz/v36n6/a05v36n6.pdf. Acesso em 23 janeiro de 2015.

12. Garcez Neto AF, Nascimento Jr D, Regazzi AJ, Fonseca DM, Mosquim PR, Gobbi KF. Respostas morfogênicas e estruturais de Panicum maximum cv. mombaça sob diferentes níveis de adubação 
nitrogenada e alturas de corte. Revista Brasileira de Zootecnia. 2002; 31(5):1890-1900. Disponível em http://www.scielo.br/pdf/rbz/v31n5/a04v31n5.pdf. Acesso em 23 janeiro de 2015.

13. Mazzantti A, Lemaire G, Gastal F. Effect of nitrogen fertilization on herbage production of tall fescue continuously grazed by sheep. II. Consumption and herbage efficiency utilization. Grass and Forage Science. 1994;49(3):352-359.Disponível em http://dx.doi.org/10.1111/j.1365-2494.1994.tb02010.x. Acesso em 23 janeiro de 2015. 